REVIEW

\title{
Incorrect radiographic evaluation after vascularized bone grafting for scaphoid fracture or nonunion
}

\author{
Paul Morin MD, Rudy Reindl MD, Gregory K Berry MD, Edward J Harvey MD MSc
}

P Morin, R Reindl, GK Berry, EJ Harvey. Incorrect radiographic evaluation after vascularized bone grafting for scaphoid fracture or nonunion. Can J Plast Surg 2011;19(1):e6-e9.

PURPOSE: The present study is a review of patients with scaphoid nonunions treated with a dorsal vascularized bone graft. The study highlights a subset of patients incorrectly diagnosed as graft failures.

METHODS: A retrospective review of patients who received vascularized grafts for scaphoid nonunions was performed over a four-year period. The vascularized graft of choice for this group was the dorsal radial extensor compartment artery.

RESULTS: Five patients from a scaphoid fracture group who were treated with vascularized grafts were diagnosed as being failures (average of five months). None of these patients had tenderness on palpation of the scaphoid, and they were scheduled for revised vascularized grafts. All patients at the time of surgery were found to have healed. These patients were treated with arthrolysis, resulting in healing and full range of motion.

CONCLUSIONS: Scaphoid vascularized grafts may have a markedly delayed radiographic healing time. Reoperation to perform secondary vascularized procedures may result in unnecessary surgery. Early imaging following a scaphoid vascularized graft may be inaccurate and may demonstrate a continued nonunion.

Key Words: Avascular necrosis; Nonunion; Scaphoid; Vascular graft

\section{Une évaluation radiographique incorrecte après la greffe osseuse vascularisée d'une fracture ou d'une pseudarthrose scaphoïde}

OBJECTIF : La présente étude est une analyse des patients ayant une pseudarthrose scaphoïde traités par greffe osseuse vascularisée dorsale. L'étude fait ressortir un sous-groupe de patients ayant obtenu un diagnostic incorrect d'échec de la greffe.

MÉTHODOLOGIE : Les chercheurs ont procédé à une analyse rétrospective menée sur une période de quatre ans auprès de patients qui ont reçu une greffe vascularisée en raison d'une pseudarthrose scaphoïde. La greffe scaphoïde privilégiée au sein de ce groupe était celle de l'artère de la loge radiale dorsale du muscle extenseur.

RÉSULTATS : Cinq patients faisant partie du groupe ayant subi une fracture scaphoïde et traités au moyen d'une greffe vascularisée ont obtenu un diagnostic d'échec de la greffe (après une moyenne de cinq mois). Aucun de ces patients n'avait de sensibilité à la palpation du scaphoïde, et ils ont obtenu un rendez-vous afin de réopérer la greffe vascularisée. Au moment de la chirurgie, la fracture de tous les patients avait guéri. Ces patients ont subi une arthrolyse, qui a assuré la cicatrisation et une amplitude complète du mouvement.

CONCLUSIONS : Les greffes vascularisées de l'os scaphoïde peuvent avoir retardé considérablement le temps de guérison à la radiographie. Il peut être inutile de procéder à une nouvelle opération en vue d'effectuer des interventions vascularisées secondaires. Une imagerie précoce après une greffe vascularisée scaphoïde peut être inexacte et démontrer le maintien de la pseudarthrose.

patients were from a single surgeon's practice. A minimum two-year clinical follow-up was implemented. The vascularized graft of choice for this group was the dorsal radial extensor compartment artery (1-2 EICA) (15,16). Rigid internal fixation with either an Acutrak mini screw (Acumed LLC, USA) or a $2 \mathrm{~mm}$ AO modular screw (Synthes Canada) inserted in a lag fashion was accomplished in patients who needed stabilization. The graft was inserted after the screw or fixation device was in place. If there was already an internal fixation device solidly in place, it was not removed. The graft was used as an adjunct to fixation. Normal follow-up for this group of patients was return to clinic for suture removal and cast at one week, and then radiographic examinations at six weeks, three months, six months, 12 months and annually after that time. At six weeks, the patient's wrist was placed in a thermoplastic splint and range of motion under physiotherapy guidelines was instituted. If there was failure of radiographic union at the three-month visit, the patient was prescribed to remain in a removable thermoplastic splint. The patient had radiographic examinations performed on a monthly basis until union occurred or the patient was brought back to the operating room. experience with this graft has shown a delayed union in a higher percentage of patients. A small group of patients had delayed union on radiographic studies, but at the time of exploration had a united fracture. This phenomenon was seen in postoperative patients with wrist arthrofibrosis and no pain on palpation over the scaphoid. The purpose of the present study is to delineate this small group of vascularized graft failure patients who may not require further surgery.

\section{METHODS}

A retrospective review of patients who received vascularized grafts for scaphoid nonunions was performed over a four-year period; the

\section{RESULTS}

Forty-two patients received a dorsal vascular graft for scaphoid fracture or nonunion as an isolated procedure. The reasons for choosing a primary vascularized graft included very proximal pole fracture, avascular proximal segment (evaluated at the time of surgery by punctate bleeding absence or with infused magnetic resonance imaging [MRI] study) without humpback deformity and proximal pole fractures in professional athletes. Ten patients with an avascular proximal pole and a humpback

Division of Orthopedic Surgery, Montreal General Hospital, McGill University Health Centre, Montreal, Quebec

Correspondence: Dr Edward J Harvey, Division of Orthopedic Surgery, Montreal General Hospital, Room B5.159.5, 1650 Cedar Avenue, Montreal,

Quebec H3G 1A4. Telephone 514-934-1934 ext 42734, e-mail edward.harvey@muhc.mcgill.ca 

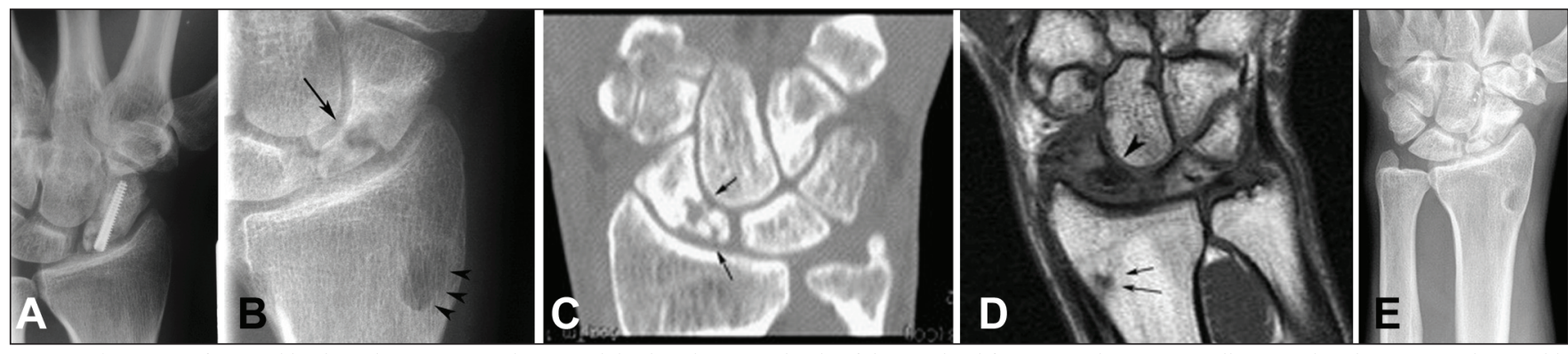

Figure 1) A A professional hockey player sustained a missed displaced proximal pole of the scaphoid fracture. This was initially treated with a retrograde variable pitch screw, and he was allowed to return to daily activity. He presented at three months with a nonunion on plain films. Early collapse and pain resulted in surgery, in which a pedicled vascularized graft from the distal radius was used. He had removal of his screw at this time as a possible etiology of his wrist pain. The graft was used as an internal strut to allow reduction. It was judged that the scaphoid was stable in position and did not require another fixation. B At three months, there was still radiographic evidence of a nonunion. Plain films showed the donor site (arrowheads) and the present line in the scaphoid (arrow). $\mathrm{C}$ Coronal cut from a computed tomography scan showed obvious nonunion of both the graft and the fracture sites (arrows). D Magnetic resonance imaging scan obtained at the same time revealed healing donor site (arrows) and probable nonunion (arrowhead). However, there was some vascular blush in the total scaphoid. Surgery at that time revealed that there was arthrofibrosis at the dorsal wrist in particular, which limited wrist motion. The scaphoid was healed despite the computed tomography scan and plain film appearance. E Follow-up radiographs at four years showed an intact scaphoid with radiolucent lines and some mild radiocarpal arthritis. The patient continues to retain his job as a professional hockey player

deformity of the scaphoid were treated in a staged manner with volar structural graft and, at six weeks, were treated with a dorsal pedicle graft. These patients were not included in the present review because they had a natural delayed healing pattern, although all of these fractures did unite.

Fourteen patients were initially seen in the clinic and primarily treated with a vascularized bone graft. Eighteen patients had previous surgery before their vascularized graft. This surgery was either percutaneous pinning or screw fixation of their fracture through a volar approach. Two patients were noncompliant after vascularized grafting. One patient was incarcerated and had his cast removed and did not return to follow-up for one year. The other patient removed his own cast at one week and did not return to follow-up for five months, at which time he complained of wrist pain similar to his initial symptoms. He had a persistent fracture line, but opted for no further surgery.

Of the 30 remaining patients with a dorsal approach to the scaphoid for vascularized grafting, 25 united radiographically and clinically at six weeks. Five patients were diagnosed as being vascularized graft failures on radiographic examination (average of five months). Delay in diagnosis occurred because the clinical examination for all patients was not convincing of a continued nonunion. These patients had wrist stiffness and described pain only at the extremes of motion. None of the patients had tenderness on palpation of the scaphoid or the snuffbox area, and did not complain of localized pain during range of motion and daily activity. Radiographic studies, including plain films and dynamic fluoroscan (computed tomography scan and MRI, if possible), showed a continued fracture or nonunion line (Figure 1). Patients who underwent an MRI had some blood flow apparent on the scan within the proximal pole. All five patients were brought back to the operating room for a vascularized graft revision. Four patients were operated in the same institution by the same surgeon, while one patient received his second surgery at another institute. All patients were found to be healed, with direct observation of an intact scaphoid (cartilage cap) at the time of their operation. These patients were all found to have extensive arthrofibrosis of the wrist that was treated with an arthrolysis. Full passive range of motion was attained before leaving the operating room. After arthrolysis, first radiographic examinations at six weeks postsurgery revealed healing or healed fractures in all patients. This was judged by a closing or closed bone gap on radiographs, with eventual bridging trabeculae.

\section{DISCUSSION}

There is no doubt that the surgical treatment of scaphoid fractures and nonunions, particularly displaced injuries, has improved dramatically.
Because of the poor prognosis of conventional bone grafts, in some centres including Montreal General Hospital, vascularized bone grafts are being used as primary treatment when avascular necrosis is present or suspected (10). A meta-analysis of evidence-based articles $(2,3)$ showed a union rate double that of nonvascularized grafts ( $88 \%$ versus $47 \%$ ). The vascularized bone graft described by Zaidemberg et al (9) was probably the first such graft in common use for scaphoid nonunion. The difficulty with visualizing the vessels at the rim of the radius has made it less popular with most hand surgeons, although reports of its efficacy continue to be published. Other grafts have been explored $(17,18)$. Currently, the most commonly used is the branch of the radial artery that courses between the first and second dorsal compartments and has a consistent supply to the radius bone at that area (1-2 EICA) $(11,12)$. This graft is a workhorse-type graft, with diverse treatment areas possible due to its effective length. This was the graft used for all patients in the present review.

In the present study, the surgeon made the diagnosis of graft failure after radiographic imaging demonstrated continued nonunion with no sign of graft incorporation (either proximally, distally or both). For this graft technique, healing is expected at 11 to 16 weeks $(15,16)$. The clinical examination for all patients was not convincing of a continued scaphoid nonunion. None of the patients described radial-sided pain; all of the patients were very stiff and described pain only at the extremes of motion. None of the patients experienced localized tenderness on palpation in the anatomical snuffbox.

Five patients were believed to have delayed union without progression of healing on radiographic examination. Four of the patients were brought back to the operating room at the same institution for a vascularized scaphoid graft revision. At the time of the surgery, all patients were found to have a united scaphoid with incorporation of the vascularized graft. These four patients, however, were found to have extensive arthrofibrosis of the wrist that was treated with an arthrolysis. This was particularly radiocarpal in nature at the site of the previous graft pedicle and extended down into the joint. Full passive range of motion was attained before leaving the operating room. The other patient was treated at another institution and was also healed, and had arthrofibrosis of the wrist that was treated with an arthrolysis, with full passive motion attained at the end of surgery.

Despite the imaging studies that demonstrated an apparent continued nonunion, the scaphoid fractures of all five of these patients had healed. Following arthrolysis and postoperative physiotherapy to maintain their range of motion, the follow-up examinations demonstrated only a slightly decreased range of motion, no functional limitations and no pain. After arthrolysis, the first radiographic examinations 
at six weeks postsurgery revealed healing or healed fractures in all patients.

It is not surprising that the group of patients with scaphoid fractures experienced some complications. Even though the overwhelming majority of reports in the literature have an extremely high union rate after vascularized grafts, there are other studies that report low union rates. A mere $60 \%$ union rate was reported by Boyer et al (19) with patient dissatisfaction also due to decreased wrist motion or scaphoid pain. Straw et al (6) published their results with only two of 16 avascular nonunions united at one- to three-year follow-up (6). They even believed that a Zaidemberg-type graft might not be warranted in patients with avascular proximal poles. The group of patients in the present study represents a new finding of arthrofibrosis associated with radiographic delayed union. It is difficult to say why this has occurred due to the fact that at exploration, the fractures had all united. There is a tendency to produce fibroblasts at a nonstable fracture interface. Large avascular portions of bone must undergo extensive revascularization and, hence, remodelling to produce union. Grafts with a less robust blood supply may also take longer to perform, increasing the chances of loose fixation and/or fibrocyte proliferation. Arthrofibrosis itself may cause a solid pseudoarthrodesis between the radius and the proximal pole of the scaphoid, allowing a continued fracture line with micromotion despite partial healing of the scaphoid graft. Release of the arthrofibrosis may allow normal healing to progress quickly; thus, the early healing process can be seen at follow-up.

Anderson et al (20) tried to assess the value of MRI scans with regard to union, graft viability and proximal pole bone marrow status after use of vascularized bone grafts for treating scaphoid nonunions. They found graft failure with persistent pseudoarthrosis and avascular necrosis of the scaphoid in four of 13 patients (31\%). Their patients had no blood return to the proximal pole, unlike our three patients. They believed that whenever blood flow returned postsurgery, the scaphoid went on to heal. However, they did not comment on the incidence of persistent fracture lines at early follow-up.

Dailiana et al (21) also studied vascularized bone grafts from the distal radius used to treat 47 scaphoid nonunions resulting from fractures or enchondromas. They had a subgroup of 15 patients incompletely assessed with MRI scans. It is interesting to note their MRI and clinical correlated results. At three months, union was established with plain radiographs in 12 patients at both sides of the graft and in three patients between the graft and proximal pole. At three months, plain MRI showed nonunion in four patients (two between the graft and proximal pole, two between the graft and distal pole, and one at both sides of the graft), whereas contrast-enhanced MRI revealed only one case of nonunion between graft and proximal pole.

\section{REFERENCES}

1. Cooney WP III, Dobyns JH, Linscheid RL. Nonunion of the scaphoid: Analysis of the results from bone grafting. J Hand Surg Am 1980;5:343-54.

2. Merrell GA, Wolfe SW, Slade JF III. Treatment of scaphoid nonunions: Quantitative meta-analysis of the literature. J Hand Surg Am 2002;27:685-91.

3. Munk B, Larsen CF. Bone grafting the scaphoid nonunion: A systematic review of 147 publications including 5,246 cases of scaphoid nonunion. Acta Orthop Scand 2004;75:618-29.

4. Fernandez DL, Eggli S. Non-union of the scaphoid. Revascularization of the proximal pole with implantation of a vascular bundle and bone-grafting. J Bone Joint Surg Am 1995;77:883-93.

5. Shin AY, Bishop AT. Pedicled vascularized bone grafts for disorders of the carpus: Scaphoid nonunion and kienbock's disease. J Am Acad Orthop Surg 2002;10:210-6.

6. Straw RG, Davis TR, Dias JJ. Scaphoid nonunion: Treatment with a pedicled vascularized bone graft based on the 1,2 intercompartmental supraretinacular branch of the radial artery. J Hand Surg Br 2002;27:413.

7. Sunagawa T, Bishop AT, Muramatsu K. Role of conventional and vascularized bone grafts in scaphoid nonunion with avascular necrosis: A canine experimental study. J Hand Surg Am 2000;25:849-59.
Reports other than the present study do hint that there may be less than a $100 \%$ chance of healing with even an appropriately performed pedicled graft. Some patients do progress to some degree of wrist arthrofibrosis. Early imaging following this vascularized graft may be inaccurate and may demonstrate a continued nonunion in the face of an incorporated graft and a united fracture. However, in cases in which an MRI $(22,23)$ shows blood flow in the proximal pole, data from this study and others in the literature seem to indicate that even if other imaging modalities show delay or nonprogression of the healing process, the scaphoid will eventually heal. Arthrolysis may be required to speed up the process; however, since these initial five patients were identified, there have been two other patients at the same institution with delayed union and decreased range of motion at four months. These patients were observed without surgery and allowed full mobility of their wrist with mobilization in physiotherapy. Both of these patients were found to have healed clinically at a further two-month follow-up and have returned to normal activities. They may have been taken back for revision surgery, if not for the present review. Stiffness due to arthrofibrosis seems to be a problem postoperatively and may confuse the clinical picture. Perhaps patients should be mobilized earlier or a more aggressive rehabilitation program initiated when range of motion exercises begin. The same meta-analysis (2) that reviewed more than 1100 studies, of which only 36 met the evidence-based criteria, revealed that postoperative splinting after obtaining solid screw fixation may not be necessary. The postoperative regimen for this institution of prolonged splinting until radiographic union may be unwarranted, and perhaps part of the problem with delayed nonunions or at least wrist arthrofibrosis. There definitely still exists the clinical entity of a nonunion after vascularized scaphoid grafting. The literature supports this finding and patients with that diagnosis present with radiographic failure, pain over the scaphoid or snuffbox and probably have MRI results consistent with no circulatory return in the proximal pole.

\section{CONCLUSION}

Early imaging by plain radiographic examinations following a scaphoid vascularized graft may be inaccurate, and actually demonstrate a continued nonunion in spite of a united fracture. This phenomenon was particularly exhibited in patients with wrist arthrofibrosis and diffuse pain to palpation over the scaphoid area. Scaphoid vascularized grafts may have a markedly delayed radiographic healing time. Reoperation to perform secondary vascularized procedures may result in unnecessary surgery.

8. Yuceturk A, Tuncay C, Isiklar U, et al. Vascularised bone graft applications in upper extremity problems. Microsurgery 1998;18:160-2.

9. Zaidemberg C, Siebert JW, Angrigiani C. A new vascularized bone graft for scaphoid nonunion. J Hand Surg Am 1991;16:474-8.

10. Waitayawinyu T, McCallister WV, Katolik LI, et al. Outcome after vascularized bone grafting of scaphoid nonunions with avascular necrosis. J Hand Surg Am 2009;34:387-94.

11. Tu YK, Bishop AT, Kato T, et al. Experimental carpal reverse-flow pedicle vascularized bone grafts. Part ii: Bone blood flow measurement by radioactive-labeled microspheres in a canine model. J Hand Surg Am 2000;25:46-54.

12. Tu YK, Bishop AT, Kato T, et al. Experimental carpal reverse-flow pedicle vascularized bone grafts. Part i: The anatomical basis of vascularized pedicle bone grafts based on the canine distal radius and ulna. J Hand Surg Am 2000;25:34-45.

13. Sheetz KK, Bishop AT, Berger RA. The arterial blood supply of the distal radius and ulna and its potential use in vascularized pedicled bone grafts. J Hand Surg Am 1995;20:902-14.

14. Kuhlmann JN, Mimoun M, Boabighi A, et al. Vascularized bone graft pedicled on the volar carpal artery for non-union of the scaphoid. J Hand Surg Br 1987;12:203-10. 
15. Chang MA, Bishop AT, Moran SL, et al. The outcomes and complications of 1,2-intercompartmental supraretinacular artery pedicled vascularized bone grafting of scaphoid nonunions. J Hand Surg Am 2006;31:387-96.

16. Steinmann SP, Bishop AT, Berger RA. Use of the 1,2 intercompartmental supraretinacular artery as a vascularized pedicle bone graft for difficult scaphoid nonunion. J Hand Surg Am 2002;27:391-401.

17. Jones DB Jr, Burger H, Bishop AT, et al. Treatment of scaphoid waist nonunions with an avascular proximal pole and carpal collapse. Surgical technique. J Bone Joint Surg Am 2009;91(Suppl 2):169-83.

18. Lanzetta M. Scaphoid reconstruction by a free vascularized osteochondral graft from the rib: A case report. Microsurgery 2009;29:420-4.

19. Boyer MI, von Schroeder HP, Axelrod TS. Scaphoid nonunion with avascular necrosis of the proximal pole. Treatment with a vascularized bone graft from the dorsum of the distal radius. J Hand Surg Br 1998;23:686-90.

20. Anderson SE, Steinbach LS, Tschering-Vogel D, et al. MR imaging of avascular scaphoid nonunion before and after vascularized bone grafting. Skeletal Radiol 2005;34:314-20.

21. Dailiana ZH, Zachos V, Varitimidis S, et al. Scaphoid nonunions treated with vascularised bone grafts: MRI assessment. Eur J Radiol 2004;50:217-24.

22. Dawson JS, Martel AL, Davis TR. Scaphoid blood flow and acute fracture healing. A dynamic MRI study with enhancement with gadolinium. J Bone Joint Surg Br 2001;83:809-14.

23. Singh AK, Davis TR, Dawson JS, et al. Gadolinium enhanced MR assessment of proximal fragment vascularity in nonunions after scaphoid fracture: Does it predict the outcome of reconstructive surgery? J Hand Surg Br 2004;29:444-8. 